\section{$17.09-19.09 .2009$}

Dublin

Ireland

..........

01.10.-03.10.2009

Budapest

Hungary

...............

04.10.-09.10.2009

Bangkok

Thailand

•.................

22.10.-24.10.2009

Alpbach

Austria

...............

24.10.-28.10.2009

Washington D.C.

USA

.................

05.11.-07.11.2009

Berlin

Germany

•................

27.11.-28.11.2009

Freiburg i.Br.

Germany

\section{… . . . . . . . .}

Stockholm

Sweden

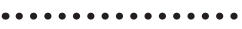

25.05.-28.05.2011

Istanbul

Turkey

.................

31.08.-03.09.2011

Hamburg

Germany
19. Workshop of the European Childhood Obesity Group

2nd Central European Congress on Obesity

9th International Congress of Nutrition (ICN 2009)

Kongress Essstörungen 2009

17. Internationale wissenschaftliche Tagung

The Obesity Society 2009 Annual Scientific Meeting

Jahrestagung 2009 der Deutschen Adipositas-Gesellschaft + Herbsttagung der Deutschen Diabetes-Gesellschaft

Freiburger Diabetestage mit Diabeteskongress Baden-Württemberg

11. International Congress on Obesity (IOC)

18th European Congress on Obesity (ECO)

XVI World Congress of the International Federation for the Surgery of Obesity and Metabolic Disorders
Information: www.ecog-obesity.eu/dublin2009

Information: cecon@asszisztencia.hu

www.cecon2009.hu

Information: AsiaCongress Events Co., Bangkok icn2009@asiacongress.com

www.icn2009.com

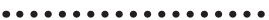

Information: Netzwerk Essstörungen, Innsbruck

info@netzwerk-essstoerungen.at

www.netzwerk-essstoerungen.at

Information: education@obesity.org

www.obesity.org

Information: K.I.T. GmbH, Berlin

Tel. +49 3024603-0, Fax -200

info@kit-group.org

Information: Intercongress

Tel. +49 761 69699-0, Fax -11

info.freiburg@intercongress.de

www.freiburger-diabetestage.de

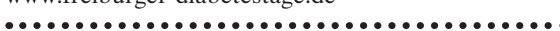

Information: IASO / Obesity International Trading

Ltd, 231 North Gower Street, London, UK

Tel. +44 207-6911900, Fax -3876033

ico2010@iaso.org

www.ico2010.org

Information: conferences@easo.org

www.easoobesity.org

Information: INTERPLAN Congress, Meeting \&

Event Management AG, Albert-Rosshaupter-Straße 65,

81369 München, Germany

Tel. +49 89 548234-0, Fax -44

info@interplan.de

www.ifso2011.de

\section{KARGER}

Fax +497614520714

Information@Karger.de

www.karger.com
(C) 2009 S. Karger GmbH, Freiburg 